\title{
OPEN Publisher Correction: SOX9 regulated matrix proteins are increased in patients serum and correlate with severity of liver fibrosis
}

\author{
Varinder S. Athwal $\mathbb{D}^{1,2,3}$, James Pritchett $\mathbb{D}^{1,2,4}$, Katherine Martin ${ }^{1,2,3}$, Jessica Llewellyn ${ }^{2}$, \\ Jennifer Scott ${ }^{1,2,3}$, Emma Harvey ${ }^{2}$, Abed M. Zaitoun ${ }^{5}$, Aoibheann F. Mullan ${ }^{1,2,3}$, \\ Leo A. H. Zeef ${ }^{6}$, Scott L. Friedman ${ }^{7}{ }^{7}$, William L. Irving ${ }^{8,9}$, Neil A. Hanley ${ }^{2,3}$, Indra N. Guha ${ }^{8}$ \\ \& Karen Piper Hanley ${ }^{1,2,3}$ \\ Correction to: Scientific Reports https://doi.org/10.1038/s41598-018-36037-4, published online 17 December \\ 2018
}

In the original version of this Article, the author Karen Piper Hanley was incorrectly indexed. This error has now been corrected.

\begin{abstract}
(c) License, which permits use, sharing, adaptation, distribution and reproduction in any medium or format, as long as you give appropriate credit to the original author(s) and the source, provide a link to the Creative Commons license, and indicate if changes were made. The images or other third party material in this article are included in the article's Creative Commons license, unless indicated otherwise in a credit line to the material. If material is not included in the article's Creative Commons license and your intended use is not permitted by statutory regulation or exceeds the permitted use, you will need to obtain permission directly from the copyright holder. To view a copy of this license, visit http://creativecommons.org/licenses/by/4.0/.
\end{abstract}

(c) The Author(s) 2019

\footnotetext{
${ }^{1}$ Wellcome Centre for Cell-Matrix Research, Faculty of Biology, Medicine \& Health, Manchester Academic Health Science Centre, University of Manchester, Oxford Road, Manchester, M13 9PT, UK. ${ }^{2}$ Division of Diabetes, Endocrinology and Gastroenterology, Faculty of Biology, Medicine \& Health, University of Manchester, Manchester Academic Health Science Centre, Oxford Road, Manchester, UK. ${ }^{3}$ Research \& Innovation Division, Central Manchester University Hospitals NHS Foundation Trust, Oxford Road, Manchester, M13 9PT, UK. ${ }^{4}$ School of Healthcare Science, Manchester Metropolitan University, Manchester, M1 5GD, UK. ${ }^{5}$ Department of Cellular Pathology, NIHR Biomedical Research Centre, Nottingham University Hospitals NHS Trust and University of Nottingham, Nottingham, UK. ${ }^{6}$ Bioinformatics Core Facility, Faculty of Life Sciences, University of Manchester, Manchester, UK. ' Division of Liver Diseases, Icahn School of Medicine at Mount Sinai, New York, NY10029, USA. ${ }^{8}$ NIHR Biomedical Research Centre, Nottingham University Hospitals NHS Trust and University of Nottingham, Nottingham, UK. ${ }^{9}$ School of Life Sciences, NIHR Biomedical Research Centre, Nottingham University Hospitals NHS Trust and University of Nottingham, Nottingham, UK. Varinder S. Athwal and James Pritchett contributed equally. Correspondence and requests for materials should be addressed to K.P.H. (email: karen.piperhanley@manchester. ac.uk)
} 